\title{
STUDI PENGEMBANGAN KOMPONEN IMPLAN PADUAN TI6AL4V UNTUK APLIKASI BIOMEDIS DENGAN PROSES METAL INJECTION MOLDING
}

\author{
Dea Anggraheni Pusparasmi ${ }^{1}$, Bambang Suharno ${ }^{1}$, Sugeng Supriadi ${ }^{2}$ \\ Departemen Teknik Metalurgi dan Material, Universitas Indonesia, Depok, Indonesia ${ }^{1}$ \\ Departemen Teknik Mesin, Universitas Indonesia, Depok, Indonesia ${ }^{2}$ \\ dea.anggraheni@ui.ac.id
}

Submitted July 1, 2021; Revised July 8, 2021; Accepted July 15, 2021

\begin{abstract}
Abstrak
Paduan titanium Ti6A14V merupakan material yang memiliki kombinasi sifat mekanik yang diperlukan untuk implan seperti keuletan yang baik, ketahanan korosi yang tinggi dan biokompatibilitas yang baik, sehingga banyak digunakan sebagai material untuk aplikasi implan biomedis. Salah satu metode yang saat ini banyak digunakan untuk memproduksi implant Ti6A14V dengan menggunakan proses metal injection molding (MIM). Proses MIM banyak digunakan karena dapat memproduksi part dengan lebih efektif, dan biaya produksi yang lebih murah. Salah satu faktor penting dalam proses MIM adalah powder loading dari serbuk logam serta sistem binder yang digunakan sebagai material feedstock. Sehingga perlu dilakukan studi lebih lanjut dan review literatur yang mendalam terkait hal tersebut. Pencarian literatur dengan menggunakan basis data (database) digital ScienceDirect dan dibatasi pada tahun 2011-2020. Hasil studi menunjukkan bahwa baik sistem binder maupun powder loading memiliki pengaruh terhadap sifat mekanis produk hasil injeksi, hasilnya terbukti bahwa viskositas feedstock mengalami penurunan seiring dengan meningkatnya laju geser (shear rate).
\end{abstract}

Kata Kunci : Metal injection molding; Ti6Al4V; powder loading; sistem binder

\begin{abstract}
Titanium alloy Ti6Al4V is a material that has a combination of mechanical properties required for implants such as good ductility, high corrosion resistance and good biocompatibility, so it is widely used as a material for biomedical implant applications. One method that is currently widely used to produce Ti6Al4V implants is by using the metal injection molding (MIM) process. The MIM process is widely used because it can produce parts more effectively, and low-cost production. One of the important factors in the MIM process is the powder loading of metal powders and the binder system used as feedstock material. So, it is necessary to conduct further studies and in-depth literature review related to this matter. Literature search using the ScienceDirect, a digital database and limited to year 2011-2020. The results of the study show that both the binder and powder loading systems have an influence on the mechanical properties of the injection product, the results are evident that the viscosity of the feedstock decreases with the increase in the shear rate.
\end{abstract}

Key Words : Metal injection molding; Ti6Al4V; powder loading; binder system

\section{PENDAHULUAN}

Menurut data Badan Pusat Statistik (BPS) pada tahun 2017, jumlah kendaraan bermotor di Indonesia sejak tahun 2010 hingga 2017 terus mengalami peningkatan. Berdasarkan data dari BPS yang terangkum pada Statistik Transportasi Darat [1], jumlah kendaraan bermotor pada tahun 2017 mencapai 138 juta kendaraan yang didominasi oleh sepeda motor yaitu sebanyak 113 juta. Tingginya jumlah kendaraan bermotor tersebut akan meningkatkan risiko terjadinya kecelakaan lalu lintas yang juga semakin meningkat setiap tahunnya. Sedangkan menurut data jumlah kecelakaan lalu lintas yang dirilis oleh BPS pada tahun 2017 [2], setidaknya 
terdapat 103.228 kasus kecelakaan dengan korban luka berat mencapai 14.395 jiwa.

Selain berasal dari korban kecelakaan lalu lintas, kasus cidera tulang di Indonesia juga terus mengalami peningkatan setiap tahunnya. Data yang dirangkum oleh Kementerian Kesehatan menyebutkan, setidaknya terdapat 8 juta orang yang mengalami patah tulang (fraktur femur). Kasus fraktur femur merupakan yang paling sering yaitu sebesar 39\% diikuti fraktur humerus (15\%), fraktur tibia dan fibula (11\%), dimana penyebab terbesar fraktur femur adalah kecelakaan lalu lintas yang biasanya disebabkan oleh kecelekaan mobil, motor, atau kendaraan rekreasi $(62,6 \%)$ dan jatuh dari ketinggian $(37,3 \%)$ dan mayoritas adalah pria $(63,8 \%)$. Insiden fraktur femur pada wanita adalah fraktur terbanyak kedua (17,0 per 10.000 orang per tahun) dan nomer tujuh pada pria $(5,3$ per orang per tahun).4,5 Puncak distribusi usia pada fraktur femur adalah pada usia dewasa (15 - 34 tahun) dan orang tua (di atas 70 tahun) [3]. Tingginya angka kasus kerusakan tulang mendorong permintaan prostesis, komponen buatan serupa tulang yang diganti atau implan tulang. Untuk memenuhi kebutuhan prosthesis tersebut, pemerintah melakukan impor $90 \%$. Produk prostesis impor itu pun tak sesuai ukuran tulang Indonesia yang lebih pendek sehingga penanganan medis tidak optimal [4].

Sejak dua dekade terakhir, Metal Injection Moulding (MIM) mulai dikembangkan sebagai alternatif manufaktur untuk beberapa material, seperti stainless steel, paduan titanium, hingga metal matrix composite (MMC) untuk miniplate untuk implan [5]. MIM dianggap sebagai teknik pembuatan komponen yang baik untuk stainless steel, titanium dan bahan logam lainnya. Proses ini juga telah menarik perhatian selama dekade terakhir sebagai teknik yang menjanjikan untuk pembuatan komponen dari titanium yang rumit untuk berbagai aplikasi di biomedis, aerospace, otomotif dan industri lainnya. Secara historis, kebutuhan untuk menggunakan bubuk titanium halus yang bulat $(0,45 \mu \mathrm{m})$ dengan kandungan titanium dioksida yang rendah telah menghambat aplikasi industri titanium MIM dari perspektif ekonomi.

Secara umum, skema proses MIM digambarkan pada Gambar 1 yang dimulai dengan pembuatan feedstock. Feedstock merupakan serbuk logam yang telah dicampur dengan binder yang terdiri dari campuran polimer, wax, dan lubrikan. Feedstock kemudian digranulasi hingga membentuk pellet, kemudian diinjeksi dengan mesin. Mesin injeksi digunakan untuk memanaskan feedstock yang kemudian lelehannya didorong ke dalam cetakan dan dinginkan. Hasilnya disebut sebagai green part yang selanjutnya akan melalui proses debinding. Proses debinding dilakukan untuk menghilangkan binder dari logam dengan menggunakan larutan (solvent debinding) atau pemanasan pada temperature di bawah temperatur sintering (thermal debinding) dan hasil yang didapatkan berupa brown part yang telah bebas dari binder. Brown part kemudian melalui proses sintering untuk pengikatan bagian-bagian yang berporos dan menghilangkan sisa-sisa binder. Dari sini dihasilkan produk yang memiliki densitas bebas poros kurang lebih sebesar 95\% [6].

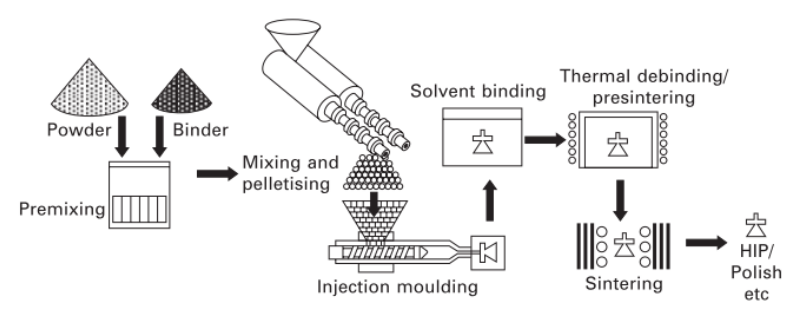

Gambar 1. Skema Proses Metal Injection Molding (MIM) [6].

Dalam proses MIM, karakteristik serbuk, powder loading, komposisi binder, dan metode pencampuran (mixing) akan mempengaruhi kualitas feedstock yang digunakan. Optimasi powder loading dan 
sistem binder dapat mempengaruhi biaya produksi menjadi lebih efektif dan efisien, serta dapat meminimalisir terjadinya defect selama proses MIM berlangsung [7]. Oleh karena itu, diperlukan studi lebih lanjut tentang pengembangan komponen paduan Ti6Al4V yang digunakan pada proses MIM selama 1 dekade terakhir untuk mengetahui tren penelitian sebelumnya serta menjadi acuan untuk melakukan riset lebih lanjut untuk pengembangan implan berbasis paduan Ti6Al4V.

\section{METODE PENELITIAN}

Pencarian data dilakukan dengan menggunakan data penelitian yang dilakukan dari tahun 2011 hingga 2020 dari basis data (database) publikasi digital bereputasi yaitu ScienceDirect dengan menggunakan kata kunci "metal injection molding" dan "titanium". Hal ini dimaksudkan agar data penelitian terbatas pada proses metal injection molding paduan titanium. Mesin pencarian dan basis data secara daring dilakukan menggunakan ScienceDirect karena berdasarkan kriteria standar pencarian basis data menurut Gusenbauer pada tahun 2020 [8], ScienceDirect memenuhi kriteria sebagai basis data pencarian untuk melakukan review sistematis. Kriteria basis data tersebut di antaranya harus relevan, transparan, dan dapat dilakukan ulang (reproducible).

Pencarian data penelitan menggunakan tiga kriteria. Kriteria pertama, data penelitian harus memiliki topik tentang metal injection molding. Kriteria kedua, topik metal injection molding dibatasi untuk aplikasi paduan titanium Ti6Al4V untuk aplikasi biomedis. Kriteria ketiga, data penelitian harus sistematis, kredibel dan logis. Sesuai dengan ketiga kriteria tersebut, dengan menggunakan kata kunci "metal injection molding titanium" diperoleh 28 data penelitian namun hanya
7 data penelitian yang memenuhi kriteria, yaitu proses MIM pada paduan Ti6Al4V. Total data penelitian yang sesuai kriteria adalah tujuh data yang disajikan pada Tabel 1.

\section{HASIL DAN PEMBAHASAN}

\section{Hasil Studi dan Review Data Penelitian}

Berdasarkan kriteria data yang digunakan, diperoleh 7 data penelitian mengenai MIM Ti6Al4V. Terdapat tiga data yang membahas tentang sifat rheologi feedstock paduan Ti6Al4V yang digunakan pada proses MIM. Tiga data selanjutnya membahas tentang sistem binder serta optimasi parameter proses yang digunakan saat melakukan MIM paduan Ti6Al4V, baik saat injeksi hingga sintering. Sedangkan satu data terakhir membahas tentang uji sampel MIM menggunakan metode tidak merusak (non-destructive test).

Wang, dkk (2013) [9] membahas tentang karakteristik rheologi paduan Ti6Al4V yang digunakan untuk aplikasi MIM. Pada penelitian tersebut digunakan serbuk $\mathrm{Ti}$ murni $99,5 \%$ dan serbuk pre-alloy $6 \mathrm{Al} 4 \mathrm{~V}$ dengan kemurnian $>99 \%$. Perbandingan komposisi keduanya 90 wt.\% serbuk titanium dan 10 wt.\% serbuk pre-alloy. Binder yang digunakan pada penelitian tersebut yaitu $60 \%$ Paraffin wax (PW), $35 \%$ Low density polyethylene (LDPE), dan $5 \%$ Strearic acid (SA) sebagai pengikat. Variasi parameter yang digunakan saat proses adalah waktu milling, powder loading, temperatur uji serta laju geser (shear rate). Sampel yang dibuat terbagi menjadi 5 dengan variasi powder loading dan waktu milling yang berbeda. Viskositas feedstock diukur dengan rheometer kapiler Instron 3211. Temperatur pengujian adalah 140, 150 dan $160^{\circ} \mathrm{C}$ dengan laju geser berada pada kisaran 4.23 hingga $1412 \mathrm{~s}^{-1}$. 
Tabel 1. Data Penelitian Tentang Metal Injection Molding paduan Ti6Al4V

\begin{tabular}{llll}
\hline No. & Data Penelitian & Serbuk Logam & Binder Polimer \\
\hline 1 & Thavanayagam, dkk (2015) & Paduan HDH Ti6Al4V & PEG, PVB, SA \\
2 & Thavanayagam, dkk (2018) & Paduan HDH Ti6Al4V & PEG, PVB, SA \\
3 & Sidambe, dkk (2013) & Ti6Al4V & PEG, PMMA, SA \\
4 & Raza, dkk (2015) & Gas atomisasi Ti6Al4V & PEG, PMMA, SA \\
5 & Thavanayagam, dkk (2019) & Paduan HDH Ti6Al4V & PEG, PVB, SA \\
6 & Lin, dkk (2017) & BE Ti6Al4V & PW, PP, PE, SA \\
7 & Wang, dkk (2013) & Ti6Al4V pre-alloy & PW, LDPE, SA \\
\hline
\end{tabular}

Untuk mengetahui efek waktu milling terhadap sifat rheologi, dilakukan pengukuran dengan variasi waktu milling selama 20, 40, dan 60 jam pada temperatur $150^{\circ} \mathrm{C}$ dan powder loading $60 \mathrm{vol} \%$.

Berdasarkan Gambar 2 diketahui viskositas menurun seiring dengan kenaikan laju gesernya. Namun seiring dengan penambahan waktu milling, viskositas juga mengalami peningkatan. Hal tersebut dikarenakan semakin lama waktu milling maka akan memperkecil ukuran partikel sehingga menyebabkan area permukaannya akan semakin besar. Studi tersebut juga menunjukkan kenaikan laju geser akan memperkecil perbedaan viskositas pada waktu milling yang berbeda. Ketika laju geser berada pada $14.12976 \mathrm{~s}^{-1}$, perbedaan viskositasnya mencapai 699.821 pascal sekon (Pa.s), sedangkan pada laju geser $423.8929 \mathrm{~s}^{-1}$ perbedaan viskositasnya turun menjadi 10.597 Pa.s. Hal tersebut dikarenakan semakin lama waktu milling, maka viskositas akan semakin sensitif terhadap laju geser. Selain itu, indeks perilaku aliran (flow behavior index) $n$ dari feedstock F3, F4, F5 dan F6 diperoleh $0.387,0.337,0.320$ dan 0.301 , secara berurutan. Hal ini berarti nilai $n$ menurun ketika powder loading meningkat.

G. Thavanayagam dkk pada tahun 2015 [10] menganalisis tentang sifat rheologi dari feedstock titanium yang diformulasikan menggunakan sistem binder terlarut dalam air. Binder merupakan salah satu faktor penting dalam menentukan keberhasilan proses MIM, sistem binder yang baik akan menghasilkan feedstock dengan sifat rheologi yang baik, sehingga dapat diperoleh produk MIM dengan sifat mekanik optimal. Kualitas feedstock dapat dilihat berdasarkan sifat reologinya. Feedstock dengan viskositas, energi aktivasi, dan indeks laju aliran yang rendah akan memiliki sifat reologi yang lebih baik untuk proses injeksi yang efektif. Energi aktivasi aliran banyak digunakan untuk menganalisis ketergantungan suhu dari viskositas dan tergantung pada komposisi pengikat dan bahan baku. Material yang digunakan pada penelitian tersebut berupa serbuk HDH-Ti6Al4V serta binder Polyethylene glycol (PEG), Polyvinyl butyral (PVB), dan Strearic acid (SA). Temperatur uji dilakukan pada suhu 125, 140 , dan $165^{\circ} \mathrm{C}$, dengan variasi beban 20 , $40,60,100$, dan $160 \mathrm{~N}$.

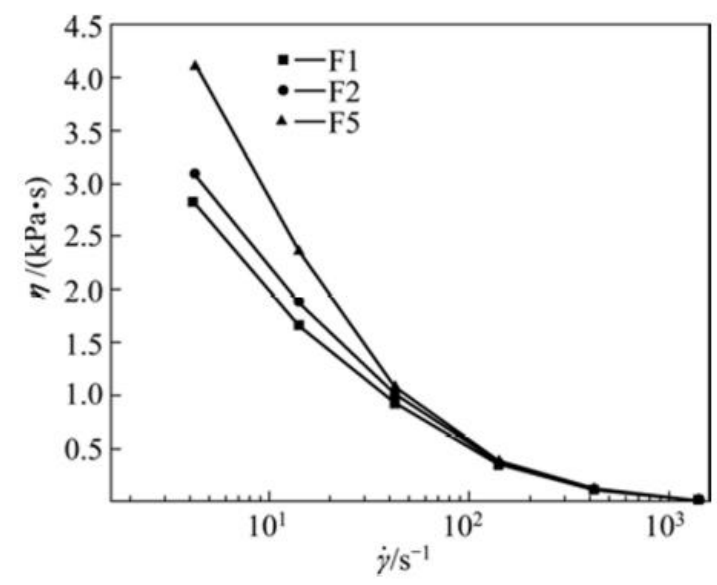

Gambar 2. Viskositas Feedstock terhadap Laju Geser pada $150^{\circ} \mathrm{C}$ [9]

Hasilnya diperoleh bahwa semua formulasi feedstock mengalami fenomena shear thinning, yang menjadi parameter keberhasilan proses MIM. Viskositas 
mengalami penurunan seiring meningkatnya laju geser, yang menunjukkan aliran non-Newtonian pseudoplastic. Berdasarkan hasil penelitian, diperoleh feedstock yang paling optimum pada komposisi 60 vol.\% HDH-Ti6Al4V, 32 vol.\% PEG, 6 vol.\% PVB dan 2 vol.\% SA karena memiliki sifat reologi terbaik, di antaranya rendah energi aktivasi, memiliki viskositas yang rendah, shear thinning dan fluiditas tinggi, dan laju aliran leleh (melt flow rate) tinggi. Energi aktivasi aliran yang tinggi menunjukkan pengaruh temperatur yang kuat terhadap viskositas. Oleh karena itu, perubahan kecil temperatur selama proses MIM dapat menyebabkan perubahan yang signifikan dalam viskositas feedstock. Viskositas dan laju geser dari semua feedstock dalam penelitian ini berada dalam kisaran $26 \mathrm{~Pa}$.s sampai 214 Pa.s pada $230 \mathrm{~s}^{-1}$ dan 14.800 $\mathrm{s}^{-1}$.

Pada tahun 2018, G. Thavanayagam dkk [11] melakukan penelitian lanjutan tentang proses debinding pada sistem binder berbasis PVB pada MIM titanium. Penelitian tersebut bertujuan untuk mengetahui efek dari perbedaan komposisi binder PEG-PVB, powder loading (55 dan $60 \mathrm{vol} \%$ ) dan parameter proses terhadap hasil MIM berbasis serbuk HDH-Ti6Al4V. Pada studi tersebut digunakan 5 variabel dengan campuran komposisi $\mathrm{HDH}-$ Ti6Al4V 55 dan 60 vol\% serta sistem binder PEG:PVB:SA 75:20:5, 80:15:5, atau 85:10:5 vol\%. Variasi temperatur injeksi MIM dilakukan pada 125, 130, 135, 140 , dan $145^{\circ} \mathrm{C}$. Sedangkan untuk proses solvent debinding dilakukan dengan variasi temperatur 35,45 dan $55^{\circ} \mathrm{C}$ selama $0.5,1$, 2, 4, 6, 10, 16 dan 24 jam. Hasil yang paling optimum didapatkan pada sampel dengan komposisi serbuk 60 vol\% $\mathrm{HDH}-$ Ti6Al4V dan binder 80:15:5 vol\% PEG:PVB:SA. Proses solvent debinding yang paling optimum terjadi pada suhu $35^{\circ} \mathrm{C}$ selama 4 jam atau $45^{\circ} \mathrm{C}$ selama 3 jam.
Penelitian lain yang dilakukan oleh G. Thavanayagam dkk (2019) [7] mempelajari tentang optimasi komposisi feedstock HDH-Ti6Al4V untuk proses MIM. Studi tersebut merupakan kelanjutan penelitian yang dilakukan pada tahun 2015 dan 2018. Pada studi ini masih digunakan serbuk HDH-Ti6Al4V serta kombinasi binder brupa PEG, PVB, dan SA. Penelitian tersebut menggunakan empat variasi komposisi binder PEG:PVB:SA vol\% 65:30:5, 75:20:5, 80:15:5 dan 85:10:5. Penelitian ini didasari oleh karakteristik serbuk, komposisi binder dan metode pencampuran keduanya yang ternyata sangat mempengaruhi hasil dan kualitas feedstock yang digunakan pada proses MIM. Sehingga, perlu dilakukan studi lebih lanjut untuk mengoptimasi keduanya untuk memaksimalkan biaya produksi yang digunakan. Hasil penelitian ini menunjukkan bahwa densitas aktual dan teoritis feedstock untuk MIM berkisar antara 40-65 vol\%. Pengukuran densitas mengindikasikan bahwa critical powder loading (CPL) untuk feedstock MIM dengan komposisi binder PEG:PVB:SA $75: 20: 5, \quad 80: 15: 5$ dan 85:10:5 vol\% berkisar antara 58-65 vol\%. Sehingga powder loading 63 vol\% dianggap sebagai hasil yang paling optimum untuk feedstock dengan komposisi binder 65:30:5 vol\%. Selanjutnya feedstock dengan komposisi 65:30:5 dan 80:20:5 vol\% dipilih sebagai acuan perbandingan, dengan pertimbangan powder loading yang optimal, biaya serta waktu produksi.

Viskositas feedstock yang terbuat dari 80:15:5 vol\% PEG:PVB:SA pada suhu $145^{\circ} \mathrm{C}$ meningkat ketika powder loading di antara 50-60 vol\%, akan tetapi masih kurang dari $100 \mathrm{~Pa} . \mathrm{s}$ dan jauh di bawah batas kritis untuk MIM yaitu 1000 Pa.s. Viskositas feedstock yang terbuat dari 5062 vol\% powder loading dan 80:15:5 vol\% PEG:PVB:SA binder adalah 50 - 1100 Pa.s dan mengalami peningkatan menjadi 38,000-50,000 pada powder loading 65 
vol\%. Powder loading kritis pada penelitian tersebut berada pada 65 vol\%, sedangkan yang paling optimum adalah 60 vol\%. Feedstocks dengan komposisi 60 vol\% serbuk Ti6Al4V dengan 75:20:5 dan 80:15:5 vol\% PEG:PVB:SA paling cocok digunakan untuk aplikasi MIM karena keduanya memiliki sifat shear thinning yang lebih tinggi dibandingkan dengan variasi lainnya.

Lin, dkk (2017) [12] melakukan studi tentang sifat rheologi dan thermal debinding feedstock MIM Ti6Al4V dan membandingkannya dengan feedstock titanium murni. Penelitian tersebut mempelajari efek penambahan paduan, critical solid loading, sifat rheologi serta dekomposisi binder. Material yang digunakan adalah serbuk BE-Ti6Al4V dengan komposisi 90 wt.\% plasma atomisasi titanium dan 10 wt.\% serbuk paduan. Sedangkan binder yang digunakan pada penelitian ini adalah 57 wt.\% Paraffin wax (PW), 25 wt.\% PP, 15 wt.\% PE dan 2,5 wt.\% SA. Hasil penelitian tersebut menyebutkan bahwa critical solid loading dari BE-Ti6Al4V adalah 66 vol\%, yang mana lebih rendah 3 vol\% dari feedstock titanium murni yaitu 69 vol\%. Sedangkan optimal solids loading untuk feedstock titanium and BE-Ti6Al4V ditetapkan pada 67 vol. \% dan 64 vol.\%, yang mana 2 vol. $\%$ lebih rendah dari nilai critical solids loading keduanya.

Raza, dkk (2015) [13] melakukan studi tentang efek system binder dan parameter proses terhadap proses pembentukan rongga (porous) komposit Ti/HA pada proses MIM. Secara garis besar, penelitian tersebut bertujuan untuk mengetahui pengaruh sistem binder yang berbasis PEG dan PW, serta parameter proses sintering terhadap pembentukan porous. Parameter yang dibahas berdasarkan aspek pengaruh sintering terhadap porositas, ukuran serta struktur rongga, dan kekuatan kompresi. Hasil penelitian tersebut menunjukkan bahwa system binder berbasis PEG yang menggunakan $\mathrm{NaCl}$ sebagai space holder cocok digunakan pada aplikasi MIM. Parameter yang paling optimum pada studi tersebut untuk proses solvent debinding adalah dengan suhu $60^{\circ} \mathrm{C}$ dan waktu tahan 5 jam, di mana pada variabel tersebut hampir keseluruhan binder PEG dan space holder $\mathrm{NaCl}$ dari green part berhasil dihilangkan tanpa membuat kerusakan pada green part. Selain itu, thermal debinding dilakukan pada suhu $500^{\circ} \mathrm{C}$ dan laju pemanasan 3C/menit selama 1 jam. Sedangkan untuk proses sintering yang paling optimum terjadi pada suhu $1300^{\circ} \mathrm{C}$ dengan laju pemanasan $10^{\circ} \mathrm{C} /$ menit dan wajtu tahan selama 5 jam. Hasil yang diperoleh menunjukkan porositas sebesar 55\% dengan kekuatan kompresi $370 \mathrm{MPa}$.

A.T. Sidambe dkk. (2013) [14] melakukan studi mengenai uji tidak merusak untuk aplikasi MIM Ti6Al4V dengan menggunakan metode Process Compensated Resonance Testing (PCRT), dan mempelajari apakah hasil dari uji tersebut dapat berhubungan dengan sifat mekanis dari produk yang dihasilkan. Penelitian ini menggunakan serbuk Ti6Al4V dan binder yang terdiri dari PEG, PMMA dan SA. Proses injeksi dilakukan pada suhu $120^{\circ} \mathrm{C}$ dan tekanan 1500 bar. Sintering dilakukan pada suhu 1250, 1300, dan $1350^{\circ} \mathrm{C}$ selama 1,2 , dan 3 jam, dengan laju pemanasan $2.5,10$ dan $20^{\circ} \mathrm{C} /$ menit dan menggunakan atmosfer argon dengan aliran rendah, tinggi, serta vakum. Setelah itu, sampel hasil sintering diuji menggunakan PCRT untuk mengetahui apakah metode PCRT cocok digunakan sebagai uji tidak merusak sampel MIM. Uji PCRT dilakukan dengan menggunakan Vibrant NDT (Sheffield) pada hasil sintering MIM Ti6Al4V sesuai dengan standar ASTM E2534. Kemampuan sistem PCRT untuk mendeteksi perubahan pada struktur internal dan permukaan titanium telah divalidasi menggunakan proof stress $0,2 \%$ dengan pengujian mekanis. Dengan 
demikian, sistem PCRT kemudian dilatih menggunakan data frekuensi PCRT yang diketahui dan proof stress $0,2 \%$ dari hasil uji merusak. Basis data dibangun menggunakan korelasi puncak frekuensi dalam prediksi proof stress $0,2 \%$. Hasilnya diperoleh bahwa korelasi frekuensi resonansi dan eksperimental proof stress $0,2 \%$ berkaitan erat, dan diperoleh nilai $\mathrm{R}>0$,9. Data korelasi juga telah berhasil digunakan untuk menunjukkan bahwa proof stress $0,2 \%$ dari paduan titanium yang dibuat melalui proses MIM dapat diprediksi menggunakan model statistik.

\section{Pembahasan}

Sebagai proses yang menghasilkan bentuk dengan tingkat presisi yang tinggi, metal injection molding (MIM) memiliki tuntutan yang sangat tinggi pada keakuratan dan variabilitas dimensi. Dalam hal ini, powder loading pada feedstock berperan penting dalam proses MIM, dan dua sifat yang paling penting adalah perilaku aliran (flow behaviour) dan viskositas. Kedua sifat ini bergantung pada karakteristik serbuk logam dan powder loading yang digunakan untuk formulasi feedstock [15]. Di satu sisi, powder loading harus memiliki nilai setinggi mungkin untuk meminimalkan terjadinya penyusutan selama proses debinding dan sintering. Namun di sisi lain, jika nilainya lebih tinggi dari critical powder loading, maka dapat mengakibatkan peningkatan keausan dan ketidakstabilan proses. Powder loading yang terlalu tinggi atau terlalu rendah dapat menimbulkan cacat berupa munculnya lapisan tipis binder yang mengalir pada produk hasil injeksi (flashing), keretakan (cracking), terjadinya penyusutan (shrinkage), serta memiliki efek yang merugikan pada presisi dimensi dan variabilitas komponen cetakan injeksi. Banyak penelitian terdahulu yang menyatakan bahwa powder loading yang optimal dapat mengurangi risiko terjadinya cacat selama proses MIM berlangsung.
Dalam proses MIM, pengisian cetakan oleh feedstock tergantung pada aliran feedstock ke dalam rongga cetakan, dan hal tersebut membutuhkan analisis sifat reologi khusus. Sifat yang paling penting adalah viskositas, karena sangat sensitif terhadap suhu dan laju geser (shear rate). Ketika laju geser meningkat, viskositas menurun, yang berpengaruh saat pembentukan bentuk pada proses injeksi. Untuk cairan dengan berat molekul rendah seperti air, viskositas tidak tergantung pada laju geser, suhu dan tekanan tertentu [16]. Cairan tersebut dikenal sebagai fluida Newtonian. Namun, konsep aliran Newtonian tersebut tidak berlaku untuk feedstock MIM. Kebanyakan polimer menunjukkan perilaku yang kompleks, di mana viskositas tergantung pada laju geser serta pada tekanan dan suhu tertentu. Fluida seperti ini disebut sebagai fluida non-Newtonian. Dalam jenis cairan tersebut, viskositas meningkat (perilaku dilatant) atau menurun (perilaku pseudoplastik) dengan meningkatnya laju geser; sedangkan, beberapa fluida menunjukkan titik tegangan luluh yang harus dilampaui untuk memulai aliran.

Berdasarkan ketiga data yang membahas tentang sifat rheologi feedstock paduan Ti6Al4V pada proses MIM yang dilakukan oleh Wang dkk [9], Thavanayagam dkk [10], dan Dongguo Lin dkk [12], ketiganya menunjukkan hasil yang serupa di mana viskositas mengalami penurunan seiring dengan meningkatnya laju geser (shear rate), hal tersebut mengindikasikan fenomena aliran pseudoplastik nonNewtonian. Persamaan yang berlaku pada fenomena ini adalah:

$\tau=k\left({ }^{\prime} \gamma\right)^{n}$

Di mana $\tau$ adalah tegangan geser, $\gamma$ adalah laju geser, $k$ adalah konstanta dan $n$ adalah eksponen aliran $(<1)$. Nilai $n$ mengindikasikan derajat sensitivitas geser. Semakin rendah nilai $n$, makan viskositas feedstock akan semakin cepat berubah 
mengikuti laju gesernya. Karena feedstock MIM bekerja di bawah pengaruh tekanan dan suhu, maka diharapkan viskositas feedstock dapat menurun seiring dengan meningkatnya laju geser saat proses injeksi terjadi.

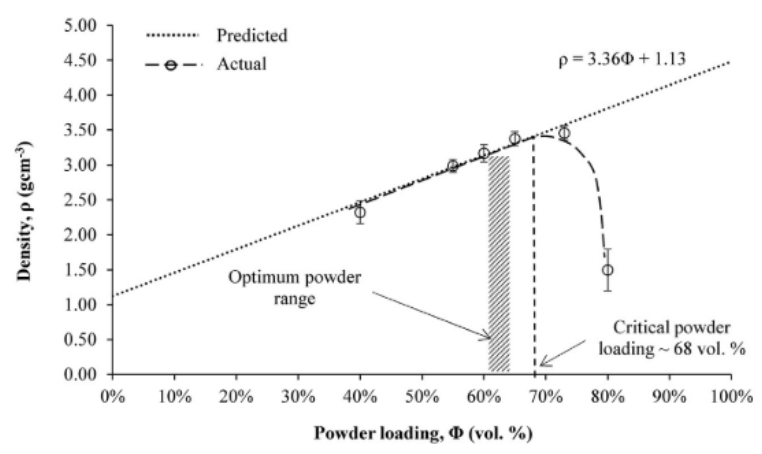

Gambar 3. Korelasi Antara Powder Loading dan Destitas Feedstock $(n=5)$ [7].

Gambar 3 merupakan prediksi korelasi aktual antara powder loading dan densitas feedstock. Terlihat densitas feedstock yang aktual dan teoritis untuk powder loading berada pada 40-65 vol\% kemudian mengalami penurunan, sehingga 68 vol $\%$ digunakan sebagai critical powder loading (CPL). Densitas aktual pada powder loading 80 vol\% hanya sekitar 39\% dari nilai teoritisnya, karena jumlah volume binder menurun dengan meningkatnya powder loading. Jika powder loading-nya rendah karena kelebihan binder dalam feedstock, maka binder dapat terpisah saat proses injeksi terjadi. Hal tersebut menyebabkan part hasil injeksi yang heterogen mengalami penyusutan selama proses debinding dan sintering. Pada titik CPL, partikel serbuk terikat dengan rapat, sehingga diperlukan sedikit binder untuk membentuk lapisan di sekitar serbuk yang mengisi ruang antar partikelnya. Jika powder loading ditingkatkan lebih lanjut, binder dapat mengisi ruang antara partikel serbuk, sehingga terjadi rongga dan densitas aktual menyimpang dari densitas teoritis. Feedstock dengan CPL memiliki viskositas tinggi (fluiditas rendah) akan sulit untuk diinjeksi. Idealnya, powder loading yang optimal berada pada 2-5 vol\% di bawah nilai CPL.

Selain powder loading, sistem binder juga memiliki pengaruh pada proses MIM. Sistem binder berfungsi untuk mengontrol perubahan bentuk pada setiap proses MIM, dan mengikat partikel serbuk logam hingga awal tahapan proses sintering. Untuk mencapai kodisi tersebut, sistem binder biasanya memiliki tiga komponen, yaitu komponen dengan berat molekul rendah untuk memberikan kemampuan mengalir yang diperlukan selama injeksi, polimer penyangga untuk mempertahankan bentuk green parts, dan surfaktan yang bertindak sebagai jembatan antara binder dan partikel bubuk [15]. Idealnya binder harus mudah dihilangkan pada laju tertentu tanpa menimbulkan cacat pada produk hasil injeksi. Green parts merupakan bagian yang paling rentan mengalami cacat selama awal proses debinding. Kekuatan polimer penyangga yang kurang baik akan menyebabkan retensi bentuk yang buruk selama tahap awal debinding.

\section{SIMPULAN}

Berdasarkan studi literatur yang telah dilakukan tentang pengembangan proses metal injection molding (MIM) paduan Ti6Al4V, dapat disimpulkan bahwa selain powder loading, sistem binder juga memiliki pengaruh pada feedstock yang digunakan pada proses MIM. Powder loading akan mempengaruhi densitas dan viskositas feedstock. Sedangkan sistem binder akan mempengaruhi sifat rheologi serta sifat mekanis pada hasil akhir produk MIM. Selain itu, uji menggunakan PCRT dapat dilakukan sebagai alternatif pengujian tidak merusak pada produk MIM. 


\section{DAFTAR PUSTAKA}

[1] B. P. Statistik, "Statistik Transportasi Darat," 2018.

[2] B. P. Statistik, "Data Kecelakaan Lalu Lintas," 2017. [Online]. Available:

https://www.bps.go.id/linkTableDin amis/view/id/1134. [Accessed: 18Dec-2019].

[3] A. Desiartama and I. W. Aryana, "Gambaran Karakteristik Pasien Fraktur Femur Akibat Kecelakaan Lalu Lintas Pada Orang Dewasa Di Rumah Sakit Umum Pusat Sanglah Denpasar Tahun 2013," E-Jurnal Med., vol. 6, no. 5, pp. 1-4, 2017.

[4] L. I. P. Indonesia, "Padukan Logam Gantikan Tulang," 2018. [Online]. Available:

http://lipi.go.id/lipimedia/PadukanLogam-Gantikan-Tulang/19869.

[Accessed: 18-Dec-2019].

[5] A. T. Sidambe, "Biocompatibility of advanced manufactured titanium implants-A review," Materials (Basel)., vol. 7, no. 12, pp. 81688188, 2014.

[6] A. Dehghan-Manshadi, M. J. Bermingham, M. S. Dargusch, D. H. StJohn, and M. Qian, "Metal injection moulding of titanium and titanium alloys: Challenges and recent development," Powder Technol., vol. 319, no. December 2018, pp. 289-301, 2017.

[7] G. Thavanayagam and J. E. Swan, "Optimizing hydride-dehydride Ti6Al-4V feedstock composition for titanium powder injection moulding," Powder Technol., vol. 355, pp. 688-699, 2019.

[8] M. Gusenbauer and N. R. Haddaway, "Which academic search systems are suitable for systematic reviews or meta-analyses? Evaluating retrieval qualities of Google Scholar, PubMed, and 26 other resources," Res. Synth.
Methods, vol. 11, no. 2, pp. 181217, 2020.

[9] J. H. Wang, Q. N. Shi, C. L. Wu, and J. Xi, "Rheological characteristics of injection molded titanium alloys powder," Trans. Nonferrous Met. Soc. China (English Ed., vol. 23, no. 9, pp. 2605-2610, 2013.

[10] G. Thavanayagam, K. L. Pickering, J. E. Swan, and P. Cao, "Analysis of rheological behaviour of titanium feedstocks formulated with a watersoluble binder system for powder injection moulding," Powder Technol., vol. 269, pp. 227-232, 2015.

[11] G. Thavanayagam and J. E. Swan, "Aqueous debinding of polyvinyl butyral based binder system for titanium metal injection moulding," Powder Technol., vol. 326, pp. 402410, 2018.

[12] D. Lin et al., "Rheological and thermal debinding properties of blended elemental Ti-6Al-4V powder injection molding feedstock," Powder Technol., vol. 311, pp. 357-363, 2017.

[13] M. R. Raza et al., "Effects of binder system and processing parameters on formability of porous Ti/HA composite through powder injection molding," Mater. Des., vol. 87, pp. 386-392, 2015.

[14] A. T. Sidambe, W. L. Choong, H. G. C. Hamilton, and I. Todd, "Correlation of metal injection moulded Ti6Al4V yield strength with resonance frequency (PCRT) measurements," Mater. Sci. Eng. A, vol. 568, pp. 220-227, 2013.

[15] P. Cao and M. D. Hayat, Feedstock Technology for Reactive Metal Injection Molding. Elsevier, 2020.

[16] D. F. Heaney, Handbook of Metal Injection Molding. 2012. 